\title{
Implementação do Jogo Torre de Hanói como Estratégia de Aprendizagem de Pilha
}

\author{
Tharles Andrade', Rafael Rodrigues Glay ${ }^{1}$, Guilherme de S. Lopes ${ }^{1}$, Renata Luiza \\ da Costa $^{1}$
}

${ }^{1}$ Departamento de Informática - Instituto Federal de Educação, Ciência e Tecnologia de Goiás (IFG)

\begin{abstract}
Av. Universitária s/n Vale das Goiabeiras - 75000-000 - Inhumas - GO - Brasil
\{tharles.andrade\}@academico.ifg.edu.br, \{rafaqwe1, guilhermeles98, rldcosta\}@gmail.com
\end{abstract}

\begin{abstract}
This paper describes the implementation of the game Tower of Hanoi in 2D using the C Programming Language, Allegro Library and the data structure called Stack. It was reported the difficulties and solutions found to use the Allegro library and for the understanding of the concept of Stack.
\end{abstract}

Resumo. Este artigo descreve a implementação do jogo Torre de Hanói em $2 D$ utilizando a linguagem de programação $C$, a biblioteca Allegro e a estrutura de dados Pilha. Foram relatadas as dificuldades e as soluções encontradas para uso da biblioteca Allegro e para a compreensão do conceito de Pilha.

\section{Introdução}

Este projeto trata do desenvolvimento do jogo Torre de Hanói numa versão digital. Por meio de várias pesquisas realizadas para decidir que jogo desenvolver, tendo em vista que o mesmo deveria adotar um dos conceitos estudados na disciplina de Estrutura de Dados, a saber lista, fila, pilha ou árvore, optou-se dentre os resultados da pesquisa, pela Torre de Hanói, por haver uma grande conformidade com a estrutura de pilha.

Sabe-se que as estruturas de dados supramencionadas requerem raciocínios complexos para sua compreensão. Além disso, teorias pedagógicas preocupadas com o desenvolvimento intelectual geral do estudante [Vygotsky 1931, 2007] explicam a fundamental importância dos alunos serem ativos nos processos de estudo começando por pesquisas espontâneas sobre um problema contextualizado e sendo direcionados para sua solução como criação progressiva da compreensão do conceito que soluciona o problema. Isso implica o abandono de abordagens pedagógicas tradicionais e a adoção de métodos em que os alunos pesquisem, estudem determinado problema, simulem, proponham soluções e exponham seus resultados, seja oralmente ou de forma escrita.

O objetivo principal de se desenvolver um jogo, desde o projeto inicial pelos alunos, foi apresentar a aplicação de um dos conceitos estudados na disciplina de Estrutura de Dados, em que, no caso dessa equipe, foi definidocomo objeto de estudo a a pilha. Segundo Sá, Teixeira e Fernandes (2007), o desenvolvimento de jogos nas atividades de ensino possibilita oferecer ao aprendiz momentos lúdicos e interativos como etapas do processo de aprendizagem. Além disso, as simulações possibilitam o desenvolvimento do raciocínio relacionando explicações do tipo causa e efeito. Para 
V Congresso Brasileiro de Informática na Educação (CBIE 2016)

Anais do XXVII Simpósio Brasileiro de Informática na Educação (SBIE 2016)

Vygotsky (1931), o desenvolvimento das faculdades mentais superiores ocorre a partir da participação em atividades que envolvem operações mentais que, posteriormente, tornam-se em ferramentas intelectuais. Assim, entendendo os jogos como situações problematizadas, contextualizadas em que há um objetivo e regras, eles podem propiciar interessantes situações de ensino-aprendizagem e, em especial, englobando a fase da criação do jogo, o que exige pesquisa e compreensão da outros conceitos interligados.

Neste sentido, o desafio do grupo foi projetar, compreender, implementar e explicar um jogo (seu problema, regras e objetivos) utilizando o conceito de Pilha com a Linguagem $\mathrm{C}$.

\section{O Processo do Desenvolvimento do Jogo}

\subsection{Conhecendo o Jogo}

O jogo Torre de Hanói é composto por três hastes fixadas em uma base com um determinado número de discos, onde os discos são organizados em ordem decrescente de tamanho a partir da base, ou seja, o menor disco sempre ficará no topo.

\subsection{Regras do Jogo}

O desafio deste jogo é mover todos os discos de uma haste para outra utilizando uma haste auxiliar e atendendo a algumas regras:

- Somente um disco pode ser movido por vez;

- Um disco maior nunca pode ser posicionado sobre um disco menor.

Apesar das regras supracitadas, o jogador não está restrito a um determinado número de movimentos; porém, o melhor resultado deverá estar dentro do número mínimo de movimentações, que é determinado pela fórmula: $\mathrm{Nm}=2^{\mathrm{d}}-1$, sendo $N m \mathrm{o}$ número mínimo de movimentos e $d$ o número de discos.

\subsection{Metodologia}

Para a implementação gráfica do jogo, foi necessário definir uma biblioteca especifica para jogos 2D. A partir das pesquisas realizadas no portal da Revista Brasileira de Informática na Educação, dos anais do SBIE e no google academics, pôde-se identificar as três mais usadas: Allegro, SDL e OpenGL. Dentre essas, a Allegro é considerada a mais popular, segundo [Mota 2002] e, por essa razão, o grupo optou por utilizá-la.

\subsubsection{Material}

As ferramentas utilizadas para o desenvolvimento do projeto foram as seguintes:

- Sistema Operacional Windows 8.1;

- $\quad$ Linguagem de programação C;

- Biblioteca Allegro 4.4;

- IDE Integrated Development Environment Code::Blocks;

- GIMP (GNU Programa de Manipulação de Imagens);

- Editor de imagens Paint. 
V Congresso Brasileiro de Informática na Educação (CBIE 2016)

Anais do XXVII Simpósio Brasileiro de Informática na Educação (SBIE 2016)

\section{Resultados: A versão final do jogo e as aprendizagens adquiridas}

Um dos resultados do desenvolvimento do projeto tratado é o próprio jogo que, desenvolvido com recursos gratuitos, ficará disponibilizado para simulações e estudo da estrutura de dados pilha em XXXX (omitido para avaliação).

O jogo possibilita que o jogador movimente os discos simulando as operações de pilha. Após a conclusão da etapa de desenvolvimento, foi possivel obter a versão final do Jogo Torre de Hanói digital, demonstrado na Figura 1.

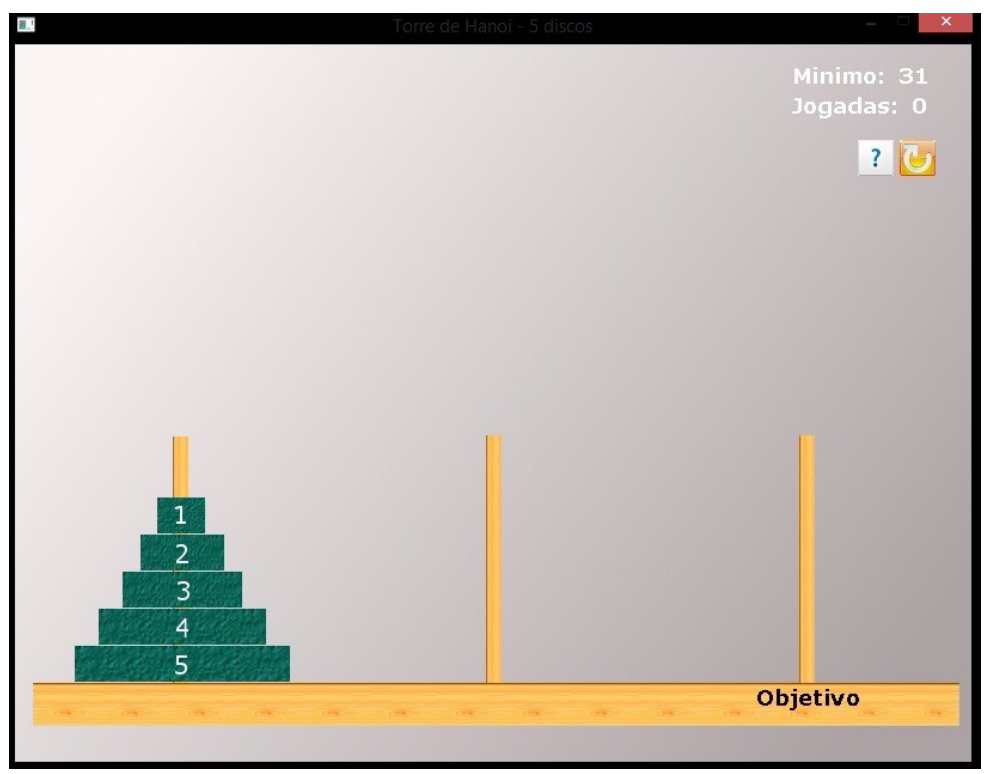

Figura 1: Tela inicial do jogo Torre de Hanói.

São disponibilizadas na tela, as infomações do status do jogo onde é possivel verificar o número mínimo de movimentos e a quantidade de movimentos executados. Também são exibidos na tela, o botão Ajuda e o botão Reiniciar, conforme a Figura 2:

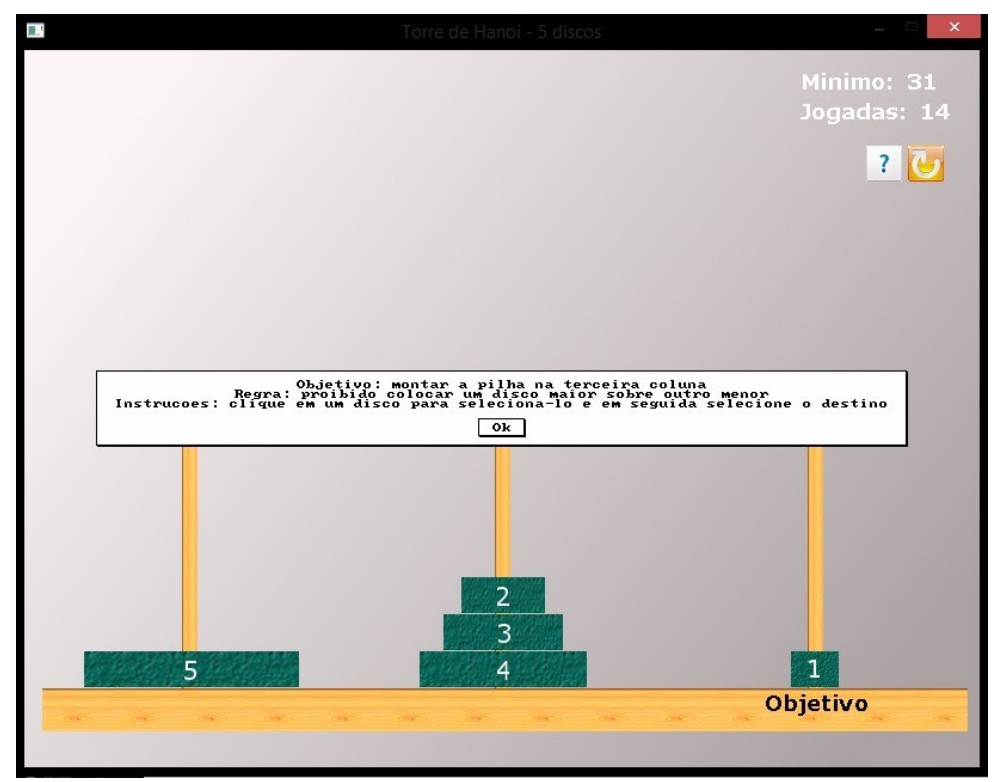

Figura 2: Jogo Torre de Hanói depois de 14 jogadas. 
Conforme mencionado anteriorme, para a realização deste projeto tornou-se necessário o uso da biblioteca Allegro em Linguagem C. A partir disso, surgiu o primeiro problema: a instalação dessa biblioteca.

A intenção da equipe era de utilizá-la em um sistema Linux. Entretanto, houve grande complexidade e, mesmo depois de vários testes com diferentes versões, não foi possível sanar esse problema e a equipe passou a utilizar a plataforma Windows.

Posteriormente, por um longo tempo, foram feitos testes com imagens para fazer a parte gráfica do jogo. O problema era que as imagens não estavam no formato compatível com a biblioteca Allegro. Finalmente, com auxílio de um tutorial muito bem explicado [Urbano 2013], foi resolvida tal questão.

Dando prosseguimento ao desenvolvimento do jogo, foi encontrado mais um problema: como usar o conceito de pilha no jogo. Logo após algumas discussões entre os integrantes do grupo, definiu-se que as três hastes do jogo seriam as pilhas. Partindo desse princípio foram criadas as structs que, por sua vez, caracterizavam os ponteiros. Logo depois foi utilizada a função malloc para alocar um espaço da memória. Depois de vários testes de mesa, chegou-se a uma solução que atendia às necessidades daquele jogo.

Segundo Pietruchinski et al. (2015), o desenvolvimento de jogos educacionais deve explorar as dimensões pedagógicas, cognitivas, psicomotoras e motivacionais, para que possam ser utilizados como elementos auxiliares nos processos de ensino e de aprendizagem. Nesse sentido, entende-se que as etapas realizadas cumprem os requisitos lúdicos para auxiliar a compreensão e esclarecer o conceito da estrutura de pliha.

\section{Conclusão}

É importante mencionar que, ao longo do desenvolvimento em que pese o fato das dificuldades iniciais mencionadas na seção anterior, foi possível aprender sobre alocação dinâmica de memória, a aplicação de structs e utilização de ponteiros na Linguagem C. Notamos que, para a aquisição do conhecimento de Pilha por meio do desenvolvimento desse jogo, várias outras habilidades foram necessárias como, por exemplo, dominar a biblioteca Allegro e a utilização de ferramentas de edição de imagens como o GIMP.

O processo de desenvolvimento do jogo Torre de Hanoi ajudou na compreensão do conceito de Pilha porque a semelhança das torres de discos com um empilhamento é grande e deixa mais clara a visualização dos movimentos possíveis naquela estrutura de dados. O jogo por si só trás um paralelo bem próximo do conceito de pilha. A implementação reforçou a aplicação deste conceito concatenado aos processos de raciocínio necessários para montá-lo no ambiente digital deixando bem explícitas as condições de uma estrutura de dados em pilha.

A partir disso, foi possível concluir que, a partir do desenvolvimento de projetos de jogos, é possível aprender, para além dos conceitos requisitados, vários outros aspectos técnicos que, associados, cooperam para a concretização do projeto em produto. Assim, foi possível vivenciar uma aplicação com o conceito de pilha e aprender vários conteúdos relacionados à Linguagem $\mathrm{C}$ necessários às outras estrutura de dados e a jogos. 
V Congresso Brasileiro de Informática na Educação (CBIE 2016)

Anais do XXVII Simpósio Brasileiro de Informática na Educação (SBIE 2016)

\section{Referências}

Pietruchinski, M. H., Neto, J. C., Reinehr, S., Malucelli, A. (2015) Processo de Desenvolvimento para Jogos Eletrônicos Educacionais: uma Revisão de Literatura. Revista Brasileira de Informática na Educação (RBIE), v. 23, n. 2.

Sá, E. J. V; Teixeira, J. S. F.; Fernandes, C.T (2007) Design de atividades de aprendizagem que usam Jogos como princípio para Cooperação. In: Anais do XVIII Simpósio Brasileiro de Informática na Educação (SBIE), São Paulo - SP, Brasil.

Urbano, A. (2013) Allegro 4. Disponível em: https://www.youtube.com/watch? $\mathrm{v}=7$ AymVV6cdG0. Acesso em 04 de Junho 2016.

Mota, T. C. A. (2002) Biblioteca Gráfica Allegro. Disponível em: http://equipe.nce.ufrj.br/adriano/c/apostila/allegro/docs/allegro.html\#primeira. Acesso em 04 de Junho 2016

Souza, J. F., Coelho, S. A. (2015). Uma biblioteca gráfica para aprendizagem de estruturas de dados e algoritmos. Revista Brasileira de Informática na Educação (RBIE), V. 23, n. 1.

Allegro. C. C. (2016) Windows Binaries. Disponível em: https://www.allegro.cc/files/? $\mathrm{v}=4.4$. Acesso em 04 de Junho 2016.

Allegro. C. C. (2016) Online Manuals. Disponível em: https://www.allegro.cc/manual/. Acesso em 04 de Junho 2016.

Vygotsky, L. S. (1991) A formação social da mente. $4^{a}$ Edição Brasileira. Livraria Martins Fontes Editora Ltda. São Paulo. SP.

Vygotsky, L. S. (2007) Pensamiento y Habla. 1ª Edição. Buenos Aires: Colihue. 